\title{
Synthesis and Characterization of Oxozirconium(IV), Dioxomolybdenum(VI) and Dioxotungsten(VI) with Ciprofloxacin and Norfloxacin Complexes
}

\author{
KHALAF I. KHALLOW and AMAAL Y.R. AL-ASSAF \\ Department of Chemistry, College of Education \\ University of Mosul, Iraq \\ kikhallow@yahoo.com
}

Received 5 July 2010; Accepted 3 September 2010

\begin{abstract}
The interaction of quinolone drugs, ciprofloxacin (CIPH) and norfloxacin (NORH), with zirconyl chloride octahydrate, sodium molybdate dihydrate and sodium tungstate dihydrate was investigated. Elemental analysis, FTIR spectral, electrical conductivity, magnetic susceptibility and UV Visible spectroscopy measurements have been used to characterize the isolated complexes. The results support the formation of two types of complexes of formula $\left[\mathrm{ZrO}\left(\mathrm{H}_{2} \mathrm{O}\right) \mathrm{L}_{2}\right] 3 \mathrm{H}_{2} \mathrm{O}$ and $\left[\mathrm{MO}_{2} \mathrm{~L}_{2}\right]$ where $\mathrm{L}=\mathrm{CIP}$ and $\mathrm{NOR} ; \mathrm{M}=\mathrm{Mo}$ and W. FTIR spectra of both types of complexes suggest that CIP and NOR act as deprotonated bidentate ligands through the ring carbonyl oxygen atom and one of the oxygen atom of carboxylic group.
\end{abstract}

Keywords: Ciprofloxacin, Norfloxacin, Oxozirconium(IV) complexes, Dioxomolybdenum(VI) complexes, Dioxotungsten(VI) complexes

\section{Introduction}

Ciprofloxacin and norfloxacin (Scheme 1) are synthetic fluoroquinolone antibacterial agents with broad spectrum of activities ${ }^{1}$ and are used for the treatment of certain disease caused by various gram negative and some gram positive microorganisms and indicated for the treatment of urinary tract infections ${ }^{2}$.<smiles>[R]N1CC(C(=O)O)C(=O)c2cc(F)c(N3CCNCC3)cc21</smiles>

[1-R-6-fluoro-1,4-dihydro-4 -oxo-7-(1-piperazinyl)-3-quinolone carboxylic acid] $\mathrm{R}=$ cyclopropyl = ciprofloxacin $=(\mathrm{CIPH}) ; \mathrm{R}=$ ethyl $=$ norfloxacin $=(\mathrm{NORH})$

Scheme 1. Formula of ciprofloxacin and norfloxacin 
Both ciprofloxacin and norfloxacin have different potential donor groups which might be involved in coordination to metal ions. Copper complex of ciprofloxacin (CIP) was isolated and its crystal structure was determined. A slight distorted square pyramid coordination around central copper ion in the structure was proposed. The quinolone molecule was bonded to the metal through carbonyl and carboxyl oxygen atoms. Two water molecules were coordinated to copper in the basal plane. The apical water molecule was coordinated at longer distance ${ }^{3}$. The complexation of $\mathrm{Zn}^{2+}$ ion with quinolone in aqueous solution depend mainly upon $\mathrm{pH}$. Two compounds were isolated. The crystal structure of the compound $\left[\mathrm{C}_{17} \mathrm{H}_{19} \mathrm{~N}_{3} \mathrm{O}_{3} \mathrm{~F}_{2}\left[\mathrm{ZnCl}_{4}\right] .2 \mathrm{H}_{2} \mathrm{O}\right.$ was determined by $\mathrm{x}$-ray diffraction which showed the structure to be ionic consisting of tetrachlorozincate dianion and two protonated monocationic ciprofloxacin molecules. Compound II $\left[\mathrm{Zn}(\mathrm{Cf})_{2}\right] \cdot 3 \mathrm{H}_{2} \mathrm{O}$ was obtained ${ }^{4}$ at adjusted $\mathrm{pH}=8$. Zupancic et al. reported that the reaction between the quinolone antibacterial agent (ciprofloxacin) (CfH)) and cobalt (II) in aqueous medium and the ability of ciprofloxacin to form metal complexes is highly dependent on the $\mathrm{pH}$ value of the solution. The isolated complexes $\left[\mathrm{Co}(\mathrm{Cf})_{2}\right] \cdot 3 \mathrm{H}_{2} \mathrm{O}$ was characterized by different techniques ${ }^{5}$.

The interaction of quinolone drugs norfloxacin and ciprofloxacin with manganese, calcium and barium perchlorate was investigated. Several spectral and physiochemical techniques were used to characterize the isolated complexes and suggested that CIP and NOR acted as bidentate ligands through the carbonyl oxygen and one of the oxygen atoms of the carboxylic group ${ }^{6}$. Moreover, the interaction of CIP with oxovanadium(IV) were studied by various methods.

Crystals of a complex $\left[\mathrm{VO}(\mathrm{CIP})_{2}\left(\mathrm{H}_{2} \mathrm{O}\right)\right]$ were isolated. Based on plausible interpretation, two anions bidentately coordinated to a vanadyl cation through carboxylate and carbonyl oxygen atoms. In addition, there was a water molecule in the coordination sphere. The reaction of CIP and NOR with iron(II) and (III) perchlorate had been investigated. The optical spectra support the formation of four types of complexes for each oxidation state with 1:1, 1:2, 1:3 and 1:4 metal to ligand molar ratio. In the four types of complexes both ligands were binded to the iron as a bidentate through the carbonyl and carboxylate oxygen atoms ${ }^{8}$. New copper(II) complex, $\left.\left[\mathrm{Cu}_{2}(\mathrm{CIP})_{2}(\mathrm{bpy})_{2}\right)(\mathrm{pip})\right] \cdot 6 \mathrm{H}_{2} \mathrm{O}$, bpy $=$ 2,2 -bipyridyl, cip = ciprofloxacin, pip = piperazinyl anion) was reported. $\mathrm{The} \mathrm{Cu}(\mathrm{II})$ ion displayed a five coordinate square pyramidal arrangement with two nitrogen donors from bpy, the carbonyl and carboxylate oxygen donors from cip and the third nitrogen atom of the pip anion occupying the fifth site ${ }^{9}$. Recently, some new complexes of ciprofloxacin-imines derived from ciprofloxacin and $p$-substituted anilines were synthesized and characterized. These ligands as well as their metal complexes were also evaluated for their antibacterial activity against several bacterial strains. It was found that the metal complexes were more active as compared to ligands ${ }^{10}$.

More recently, two iron(III) complexes of ciprofloxacin were synthesized in different solutions. Molecular complex in which the ligand was bidentately bonded to Fe(III) through the carbonyl oxygen and one of carboxylate oxygen atom and the ionic complex consisting if tetrachloroferrate ion which was electrostatically attached to the ligand ${ }^{11}$.

To the best of our knowledge, no complexes between oxozirconium(IV), dioxomolybdenum and dioxotungstin and quinolone agent, ciprofloxacin and norfloxacin, were reported yet. Hence, we in this work report the synthesis and characterization of such complexes using the spectral and physicochemical techniques to elucidate their structures. 


\section{Experimental}

Ciprofloxacin and norfloxacin used in this study were obtained from cipla drug company (India) and purified. $\mathrm{ZrOCl}_{2} .8 \mathrm{H}_{2} \mathrm{O}, \mathrm{Na}_{2} \mathrm{MoO}_{4} \cdot 2 \mathrm{H}_{2} \mathrm{O}$ and $\mathrm{Na}_{2} \mathrm{WO}_{4} \cdot 2 \mathrm{H}_{2} \mathrm{O}$ were obtained from Aldrich Chemical Company and used without further purification. Ethanol was used as solvent.

\section{Measurements}

The FTIR spectra of the complexes were recorded in $\mathrm{KBr}$ discs using Tensor 27 Bruker Co. (Germany) in the range 400-4000 $\mathrm{cm}^{-1}$. UV Vis spectra of the complexes were recorded by using Shimadzu UV-visible recording spectrophotometer UV 160 A in DMF as a solvent and range of 200-1100 nm. Molar conductance were measured using LF-42 conductivity meter.

\section{Synthesis}

In typical experiment $2 \mathrm{mmol}$ of CIPH or NORH suspended in $10 \mathrm{~mL}$ of ethanol was mixed with another solution containing $1 \mathrm{mmol}$ of the metal salt in distilled water. The reaction mixture was stirred and refluxed for $2 \mathrm{~h}$. The solution was then reduced to half its volume by evaporation and a colored precipitate complex was filtered off and washed with distilled water then dried.

\section{Results and Discussion}

Two types of complexes of formula $\left[\mathrm{ZrOL}_{2}\left(\mathrm{H}_{2} \mathrm{O}\right)\right] \cdot 3 \mathrm{H}_{2} \mathrm{O}$ and $\left[\mathrm{MO}_{2} \mathrm{~L}_{2}\right]$ were reported herein and formed from the reaction of the metal salt with the drug in 1:2 molar ratio. All of the obtained complexes were stable solids at room temperature (Table 1). Examination of solubility of these complexes showed that they were insoluble in benzene, chloroform and dichloromethane, slightly soluble in methanol and ethanol and soluble in dimethylformamide and dimethylsulfoxide. The molar conductances of the isolated complexes indicated that all the complexes were non-electrolytes ${ }^{12}$.

Table 1. Physical properties and UV-visible spectra of the ligands and their complexes

\begin{tabular}{|c|c|c|c|c|c|c|}
\hline \multirow[t]{2}{*}{ Compound } & \multirow[t]{2}{*}{ Color } & \multirow{2}{*}{$\begin{array}{c}\text { Conductivity } \\
\Delta_{\mathrm{M},} \Omega^{-1} \cdot \mathrm{mol}^{-1} . \\
\mathrm{cm}^{2}\end{array}$} & \multirow{2}{*}{$\begin{array}{l}\text { Elemental } \\
\text { analysis } \\
\text { Calc/(exp) }\end{array}$} & \multicolumn{3}{|c|}{$\begin{array}{l}\text { Electronic spectra, } \\
\mathrm{nm}\end{array}$} \\
\hline & & & & $\pi-\pi^{*}$ & $n-\pi^{*}$ & CT \\
\hline CIPH & White & - & - & 290 & 322 & 208 \\
\hline NORH & White & - & - & 288 & 318 & 248 \\
\hline$\left[\mathrm{ZrO}\left(\mathrm{H}_{2} \mathrm{O}\right)(\mathrm{CIP})_{2}\right] 3 \mathrm{H}_{2} \mathrm{O}$ & White & 30.0 & $10.8(9$ & 304 & 324 & 264 \\
\hline$\left[\mathrm{ZrO}\left(\mathrm{H}_{2} \mathrm{O}\right)(\mathrm{NOR})_{2}\right] 3 \mathrm{H}_{2} \mathrm{O}$ & Off-yellow & 11.0 & $11.1(10.95)$ & 304 & 332 & 266 \\
\hline$\left[\mathrm{MoO}_{2}(\mathrm{CIP})_{2}\right]$ & $\begin{array}{l}\text { Greenish } \\
\text { yellow }\end{array}$ & 11.5 & 12.0(11.7) & 308 & 324 & 280 \\
\hline$\left[\mathrm{MoO}_{2}(\mathrm{NOR})_{2}\right]$ & Green & 8.2 & 12.4 & 308 & 324 & 280 \\
\hline$\left[\mathrm{WO}_{2}(\mathrm{CIP})\right.$ & Yellow & 8.5 & $20.9(20.3)$ & 306 & 330 & 278 \\
\hline$\left[\mathrm{WO}_{2}(\mathrm{NOR})_{2}\right]$ & Lemon & 20.0 & $21.5(21.0)$ & 308 & 332 & 266 \\
\hline
\end{tabular}

The coordination sites of the ligands involved in the bonding with the metal ions for both type of complexes had been specified by careful comparison of the infrared spectra of the synthesized complexes with that of the parent ligands (Table 2). Both ligands showed strong broad bands near $3400 \mathrm{~cm}^{-1}$. These bands could be assigned to the vibrations of the $\mathrm{N}-\mathrm{H}$ group. This bands was unaltered in the spectra of the complexes as due to the noninvolvement of this group in the coordination with metal ions $\mathrm{s}^{3,13}$. 
Table 2. Important FTIR spectra of CIPH and NORH and their complexes

\begin{tabular}{|c|c|c|c|c|c|c|c|c|c|c|}
\hline Compound & $v \mathrm{~N}-\mathrm{H}$ & $v \mathrm{OH}$ & $v_{r}(\mathrm{OH})$ & $v_{\mathrm{w}}(\mathrm{OH})$ & $\begin{array}{c}v\left(\mathrm{COO}^{-}\right) \\
\text {asy }\end{array}$ & $\begin{array}{c}v\left(\mathrm{COO}^{-}\right) \\
\text {sy }\end{array}$ & $v \mathrm{C}=\mathrm{O}$ & $v \mathrm{M}=\mathrm{O}$ & $v M-O$ & $\begin{array}{c}\Delta v \\
\text { (asy-sy) }\end{array}$ \\
\hline $\mathrm{CIPH}$ & 3442 & - & - & - & 1624 & - & 1707 & - & - & - \\
\hline $\mathrm{NORH}$ & 3419 & - & . & - & 1620 & - & 1730 & & . & . \\
\hline $\begin{array}{c}{\left[\mathrm{ZrO}\left(\mathrm{H}_{2} \mathrm{O}\right)\right.} \\
\left.(\mathrm{CIP})_{2}\right] 3 \mathrm{H}_{2} \mathrm{O}\end{array}$ & 3445 & 3414 & 1020 & 669 & 1633 & 1426 & 1680 & 1020 & 467 & 207 \\
\hline $\begin{array}{c}{\left[\mathrm{ZrO}\left(\mathrm{H}_{2} \mathrm{O}\right)\right.} \\
\left.(\mathrm{NOR})_{2}\right] 3 \mathrm{H}_{2} \mathrm{O}\end{array}$ & 3452 & 3420 & 1015 & 656 & 1620 & 1427 & 1725 & 1015 & 440 & 193 \\
\hline$\left[\mathrm{MoO}_{2}(\mathrm{CIP})_{2}\right]$ & 3445 & - & - & - & 1634 & 1425 & 1700 & 949 & 420 & 209 \\
\hline$\left[\mathrm{MoO}_{2}(\mathrm{NOR})_{2}\right]$ & 3422 & - & - & - & 1631 & 1426 & 1720 & 1032 & 418 & 205 \\
\hline$\left[\mathrm{WO}_{2}(\mathrm{CIP})_{2}\right]$ & 3444 & - & - & - & 1629 & 1399 & 1670 & 964 & 439 & 230 \\
\hline$\left[\mathrm{WO}_{2}(\mathrm{NOR})_{2}\right]$ & 3419 & - & - & - & 1629 & 1425 & 1710 & 964 & 442 & 204 \\
\hline
\end{tabular}

Both CIPH and NORH used to have strong bands at the ranges 1610 and $1730 \mathrm{~cm}^{-1}$ and assigned before to the stretching vibration of the carboxylic $(\mathrm{vCOOH})$ and the carbonyl $(\mathrm{vCO})$ groups as reported earlier ${ }^{14,15}$. The main feature of the spectra of both CIPH and NORH were the absence of the $\mathrm{vCOOH}$ vibration, a behavior that is consistent with the deprotonation of both ligands ${ }^{16}$. Turel et al. ${ }^{15}$ assigned two bands at $1585 \mathrm{~cm}^{-1}$ and $1380 \mathrm{~cm}^{-1}$ in the spectrum of $\mathrm{COOH}$ for the asymmetric and the symmetric stretching of the deprotonated carboxylate group, respectively. The IR spectra of the ligands in the synthesized complexes (Table 2) display all features of deprotonated quinolone complexes. On complexation, the $\mathrm{vCOOH}$ stretching in both ligands disappeared and instead two bands in the region $1620-1634 \mathrm{~cm}^{-1}$ and $1399-1427 \mathrm{~cm}^{-1}$ and can reasonably assigned to the asymmetric and symmetric stretching vibration of the ligated $\mathrm{COO}^{-}$group respectively ${ }^{6}$. It was established that the carboxylate group can act as unidentate when the frequency separation $\left[\Delta v=\left(v_{\text {asy }} \mathrm{COO}^{-}-v_{\text {sy }} \mathrm{COO}^{-}\right)\right] \geq 200^{16}$. The observed $\Delta v$ for the synthesized complexes are in the range $193-230 \mathrm{~cm}^{-1}$ which suggests a unidentate interaction of the carboxylate group with the central ions in both types of complexes.

The next diagnostic band in the free ligand are that for the carbonyl group $v \mathrm{C}=\mathrm{O}$ which appeared at $1707,1730 \mathrm{~cm}^{-1}$ for CIPH and NORH respectively. This bands were negatively shifted $\left(\Delta v=7-37 \mathrm{~cm}^{-1}\right)$ and $\left(\Delta v=5-20 \mathrm{~cm}^{-1}\right)$ for CIPH and NORH complexes respectively. This interpreted as due to the coordination of the carbonyl group with the metal ions ${ }^{6-10}$. New bands were appeared in the regions $\left(949-1032 \mathrm{~cm}^{-1}\right)$ and $\left(418-467 \mathrm{~cm}^{-1)}\right.$ and assigned to $\mathrm{M}=\mathrm{O}$ stretching ${ }^{17,18}$ and $\mathrm{M}-\mathrm{O}$ stretching ${ }^{10}$ respectively.

The coordinated water in the zirconium complexes was indicated by the band observed within 3414-3420 $\mathrm{cm}^{-1}$ and two somewhat weaker bands assigned as the $\mathrm{OH}$ stretching $1015-1020 \mathrm{~cm}^{-1}$ as rocking and $656-669 \mathrm{~cm}^{-1}$ as wagging ${ }^{19}$ whereas none of these vibrations appeared in the spectra of uncoordinated ligands.

The electronic spectra of both ligands and their complexes were recorded in Table (1). Two bands appeared at $298-288 \mathrm{~nm}$ and $322-318 \mathrm{~nm}$ which can be assigned to $\pi \rightarrow \pi^{*}$ and $\mathrm{n} \rightarrow \pi^{*}$ transition in both ligands respectively ${ }^{20}$. These bands were shifted to a higher values on comparison with that of their complexes solution (Table 1). Besides, a new band at 264-280 nm were appeared in the spectra of the complexes and attributed to charge transfer transition between both ligands and their complexes ${ }^{10}$.

In conclusion, both ligands coordinated with metal ions through two oxygen atoms from the carboxylate and the carbonyl groups to give, with the presence of oxo group and water molecule in type I and dioxo group in type II, the most probable octahedral geometry around each metal ion as depicted below. 

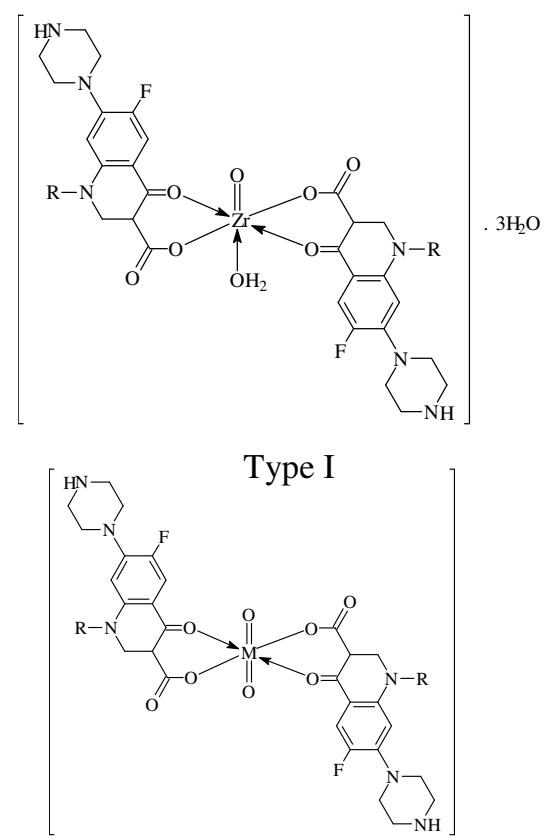

Type II

\section{References}

$$
\mathrm{M}=\mathrm{Mo}, \mathrm{W} \mathrm{R}=-\mathrm{CH}_{2} \mathrm{CH}_{3} \text {, cyclo- }-\mathrm{CH}_{2} \mathrm{CH}_{2} \mathrm{CH}-
$$

1. Ohta M and Koga H, J Med Chem., 1991, 34, 131-139.

2. Block J H and Beale J M, Wilson and Gisvold 'sTextbook of Organic Medicinal and Pharmaceutical Chemistry $11^{\text {th }}$ Ed., Lippincott, Wolters Kluwer Company, 2004, 248.

3. Turel I, Golic L and Ramirez O L R, Acta Chem Slov., 1999, 46(2), 203-211.

4. Zupancic M, Turel I, Bukovec P, White A J P and.Williams D J, Croatia Chemica Acta, 2001, 74(1), 61-74.

5. Zupancic M, Turel I, Bukovec P and Kodre A, Croatica Chemica Acta, 2002, 75(1), 1.

6. Al-Mustafa J, Acta Chim Slov., 2002, 49, 457-466.

7. Turel I, Golobic A, Klavzar A, Pihlar B, Buglyo P, Tolis E, Rehder D and Sepcic K, $J$ Inorg Biochem., 2003, 95,199-207.

8. Al-Mustafa J and Tashtoush B, J Coord Chem., 2003, 56(2), 113-124.

9. Wu G,Wang G, Fu X and Zhu L, Molecules, 2003, 8, 287-296.

10. Imran M,.Iqbal J and Ijaz N, Turk J Biol., 2007, 31, 67-72.

11. Obaleye J A, Akinremi C A , Balogun E A and Adebayo J, African J Biotechnol., 2007,6(24), 2826-2832.

12. Geary W J, Coord Chem Rev., 1971, 7, 81.

13. Silverstein R M and Webster F X, Spectrophotometric Identification of Organic Compounds, $6^{\text {th }}$ Ed., John Wiley and Sons Inc., New York,1998.

14. Gao F, Yang P, Xie J and Wang H, J Inorg Biochem., 1995, 60, 61-67.

15. Turel I, Leban I and Bukovec N, J Inorg Biochem., 1997, 66, 241-245.

16. Deacon G B and Phillips R J, Coord Chem Rev., 1980, 33, 227.

17. Kim D W, Lee U and Koo B.K, Bull Korean Chem Soc., 2004, 25(1), 1071.

18. Lehtonen A, Inorg Chem Comm., 2005, 8(1), 122.

19. Ahmed A H, Omran A A and El-Sherbiny G M, J Appl Sci Res., 2006, 2(1), 44-50.

20. Mukta J and Singh R V, Bioinorg Chem Appl., 2006, 10, 10. 


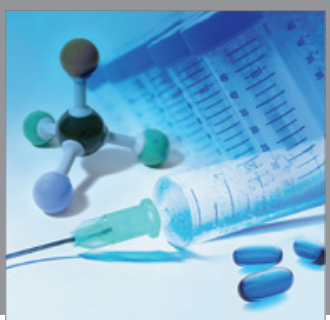

International Journal of

Medicinal Chemistry

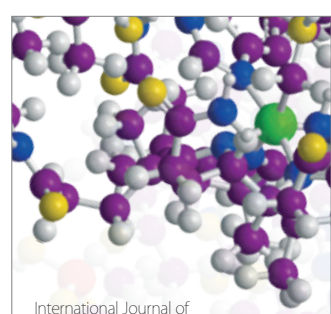

Carbohydrate Chemistry

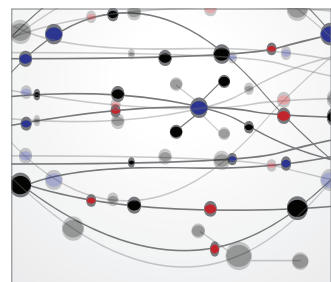

The Scientific World Journal
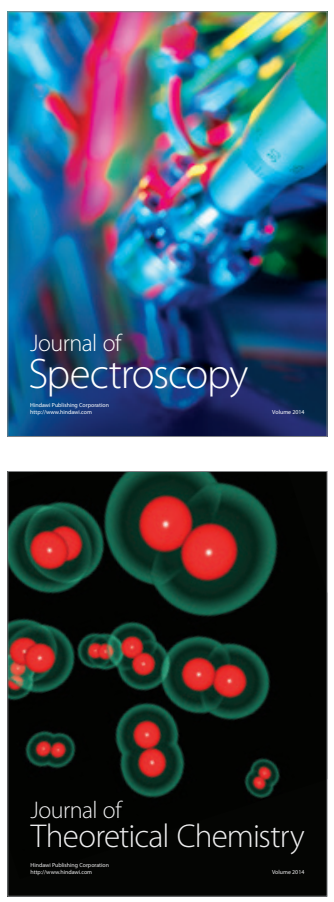
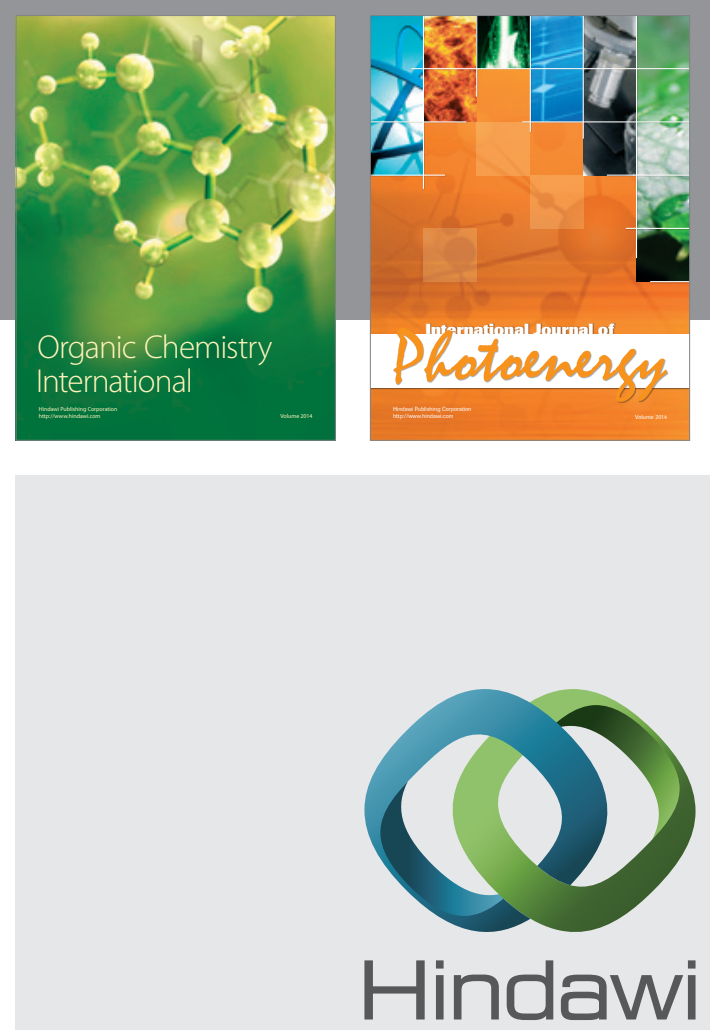

Submit your manuscripts at

http://www.hindawi.com
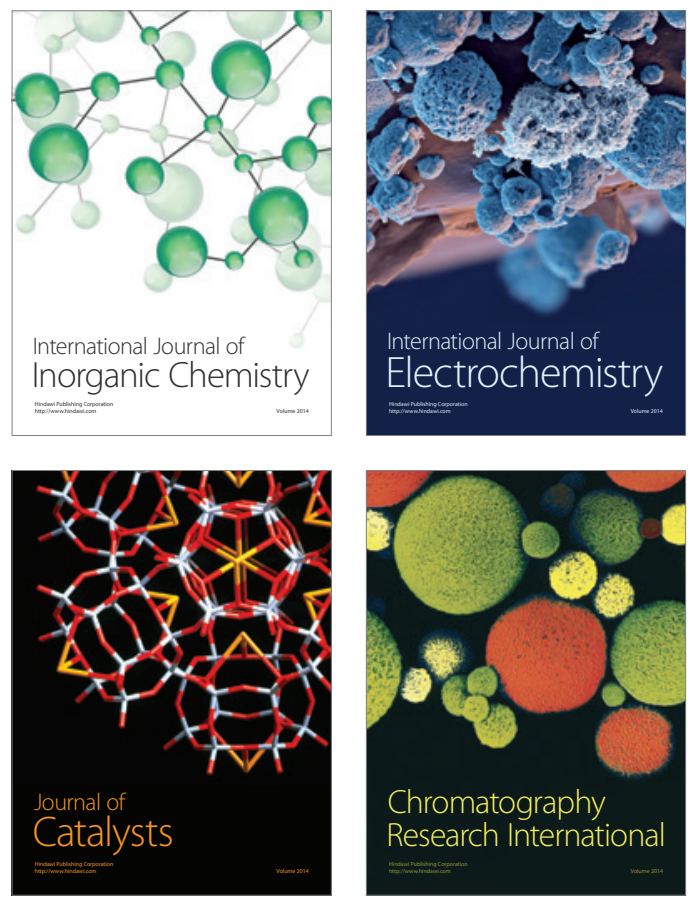
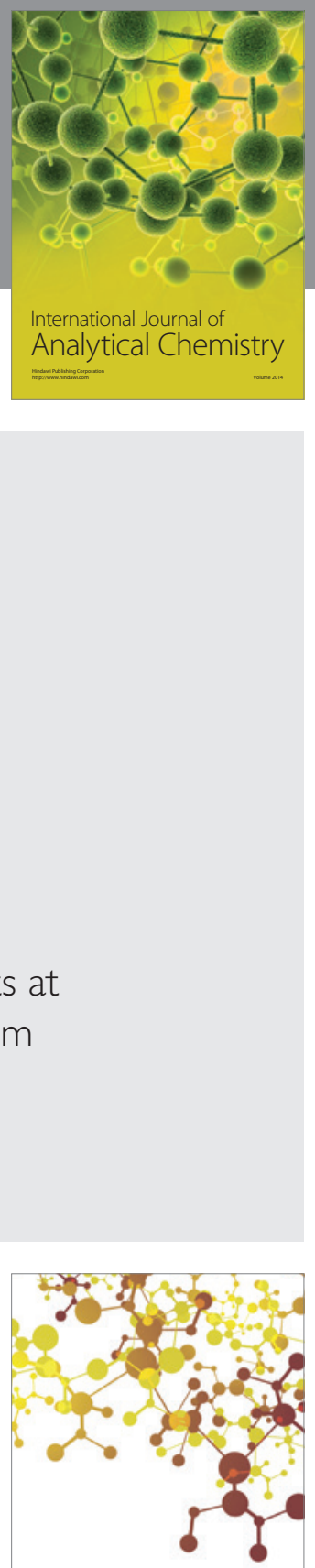

Journal of

Applied Chemistry
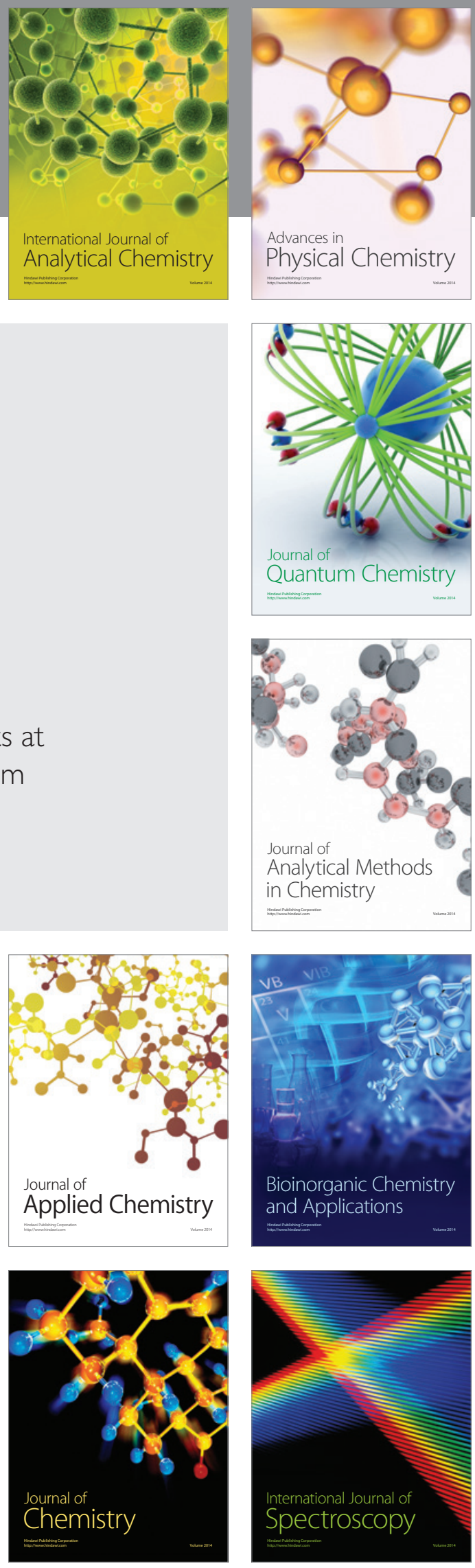